\title{
Prevalence and Correlates of Unintentional Injuries among In-School Adolescents in Ghana
}

\author{
Richard Gyan Aboagye ${ }^{1} \mathbb{D}$, Abdul-Aziz Seidu 2,3,4 ${ }^{\mathbb{D}}$, Samuel Adolf Bosoka ${ }^{5}$, John Elvis Hagan, Jr. ${ }^{6,7, *(\mathbb{D})}$ and \\ Bright Opoku Ahinkorah ${ }^{8}$ (D)
}

1 Department of Family and Community Health, School of Public Health, University of Health and Allied Sciences, Hohoe PMB 31, Ghana; raboagye18@sph.uhas.edu.gh

2 Department of Population and Health, University of Cape Coast, Cape Coast PMB TF0494, Ghana; abdul-aziz.seidu@stu.ucc.edu.gh

3 College of Public Health, Medical and Veterinary Sciences, James Cook University, Townsville, QLD 4811, Australia

4 Department of Estate Management, Takoradi Technical University, Takoradi P.O. Box 256, Ghana

5 Department of Epidemiology and Biostatistics, School of Public Health, University of Health and Allied Sciences, Hohoe PMB 31, Ghana; samuelbosoka@gmail.com

6 Physical Education and Recreation, Department of Health, University of Cape Coast, Cape Coast PMB TF0494, Ghana

7 Neurocognition and Action-Biomechanics-Research Group, Faculty of Psychology and Sports Science, Bielefeld University, Postfach 100131, 33501 Bielefeld, Germany

8 School of Public Health, Faculty of Health, University of Technology Sydney, Sydney, NSW 2007, Australia; brightahinkorah@gmail.com

check for updates

Citation: Aboagye, R.G.; Seidu, A.-A.; Bosoka, S.A.; Hagan, J.E., Jr.; Ahinkorah, B.O. Prevalence and Correlates of Unintentional Injuries among In-School Adolescents in Ghana. Int. J. Environ. Res. Public Health 2021, 18, 6800. https:// doi.org/10.3390/ijerph18136800

Academic Editors: Joanna Mazur and Paul B. Tchounwou

Received: 1 June 2021

Accepted: 21 June 2021

Published: 24 June 2021

Publisher's Note: MDPI stays neutra with regard to jurisdictional claims in published maps and institutional affiliations.

Copyright: (c) 2021 by the authors. Licensee MDPI, Basel, Switzerland. This article is an open access article distributed under the terms and conditions of the Creative Commons Attribution (CC BY) license (https:// creativecommons.org/licenses/by/ $4.0 /)$.
* Correspondence: elvis.hagan@ucc.edu.gh

Abstract: Injuries among adolescents pose significant public health problems. Unintentional injuries are the leading cause of adolescents' mortality and disability with the largest burden in low-and middle-income countries. Yet, there is paucity of data in Ghana on adolescent injuries. The present study aimed to determine the prevalence and correlates of unintentional injuries among in-school adolescents in Ghana using data from the Global School-Based Health Survey. Cross-sectional data on 2058 adolescents in junior and senior high schools who randomly participated in the 2012 Global School-Based Health Survey were analyzed. Descriptive statistics were performed to determine the prevalence of unintentional injuriesacross the background characteristics of in-school adolescents. Binary logistic regression was employed to determine the factors associated with unintentional injuries. The results were presented as crude and adjusted odds ratios at a $95 \%$ confidence interval. The prevalence of one or more serious injuries in the past 12 months was $57.0 \%$. The most commonly reported type and cause of injuries were "I had a cut or stab wound" (15.2\%) and "I fell" (13.1\%), respectively. In the adjusted regression, in-school adolescents aged $14-16(\mathrm{aOR}=1.60, \mathrm{CI}=1.12-2.28)$ were more likely to report one or more serious injuries compared to their counterparts aged 13 or younger. In-school adolescents who participated in physical education (aOR $=1.27, \mathrm{CI}=1.03-1.58)$ had higher odds of reporting one or more serious injuries. The odds of being injured was higher among adolescents who were truant at school compared to those who were not truant $(\mathrm{aOR}=1.42$, $\mathrm{CI}=1.14-1.77$ ) In-school adolescents who were bullied were more likely to report being injured one or multiple times compared to their counterparts who were not bullied ( $\mathrm{aOR}=2.16, \mathrm{CI}=1.75-2.65)$. In addition, the odds of being injured once or multiple times were higher among adolescents who were physically attacked $(\mathrm{aOR}=2.21, \mathrm{CI}=1.78-2.75)$, those that engaged in physical fighting $(\mathrm{aOR}=$ $1.94, \mathrm{CI}=1.54-2.45)$, and those who reported high psychological distress (aOR $=2.00, \mathrm{CI}=1.52-2.63)$ compared to their counterparts who were not. Conversely, adolescents in senior high schools were $39 \%$ less likely to be injured once or multiple times compared to those in junior high schools (aOR $=0.61, \mathrm{CI}=0.47-0.79$ ). A relatively high prevalence of unintentional injuries was found among in-school adolescents in the study. The numerous factors identified in this study could be integrated into health promotion and injury prevention activities to help reduce the occurrence of injuries among in-school adolescents. Moreover, students who are susceptible to unintended injuries such as older adolescents, victims of bullying, those who participate in physical education, those who are 
often involved in fights, truants, and those who have psychological distress should be sensitized to take measures that will reduce their level of susceptibility. First aid treatment services should also be made available in schools to treat victims of unintended injuries.

Keywords: adolescents; Ghana; injury; psychological distress; psychosocial; substance use

\section{Introduction}

Childhood injuries have emerged as significant public health concerns necessitating urgent attention [1-3]. Adolescent serious injury can be defined as any form of injury that can make an adolescent miss usual activities or an injury that requires medical attention [1]. In 2016, injuries accounted for more than 255 million disability-adjusted life years (DALYs) [4]. Globally, approximately 2300 children and adolescents die every day from unintentional injuries [5]. These injuries consist of road traffic injuries, drowning, poisoning, falls, and burns [3], with the former alone causing an estimated 10.2 deaths per 100,000 adolescents [5]. Road traffic injuries were the leading cause of adolescents mortality in 2016 with over 135,000 deaths [6,7], while nearly 50,000 adolescents died from drowning [7]. As a result, unintentional injuries are regarded as the leading cause of death and disability among adolescents [7]. In addition to the mortalities, injuries are associated with a lifelong disability, psychosocial problems, and financial repercussions on the injured victim and their families $[3,8,9]$. However, this burden is disproportionately distributed, with the largest problem in low- and middle-income countries, impacting adversely on the health and productivity, and the resulting pressure on social systems $[8,10]$.

A study conducted among adolescents aged 12-15 years from 68 low- and middleincome countries reported an overall $42.9 \%$ prevalence of serious injuries in the past 12 months [1]. A study by Beck et al. [11] found the prevalence of one or more serious injuries among adolescents from Argentina, Uruguay Chile, and Bolivia to be $27.1 \%, 29.5 \%$, $30.9 \%$, and $36.8 \%$ respectively. In seven Caribbean countries, the percentage of adolescents reporting one or more serious injuries within the past 12 months was $54.3 \%$ for all countries, ranging from $43.1 \%$ in Dominica to $59.5 \%$ in Jamaica [12]. Additionally, the prevalence of serious injury in the past year was $43.1 \%$ in the Cook Islands, $40.8 \%$ in Niue, $73.8 \%$ in Samoa, and $49.1 \%$ in Tonga [13].

In sub-Saharan Africa, a study conducted among adolescents in six countries showed an overall $68.2 \%$ prevalence of one or more serious injuries of which country-specific rates were Zambia (71.5\%), Kenya (71.0\%), Uganda (63.4\%), Zimbabwe (62.8\%), Namibia $(60.2 \%)$, and Swaziland (38.6\%), [14]. Similarly, findings from other studies using Global School-Based Health Survey (GSHS) data reported the prevalence of serious injuries in the following countriesMozambique (55.7\%) [15], Djibouti (61.1\%) [2], Botswana (65.8\%) [16], and Tanzania (22.14\%) [17].

Evidence suggests that factors such as sociodemographic characteristics (male sex and low socioeconomic status) [14,17-22] substance use (alcohol, tobacco, smoking, drugs) [2, $14,15,18,20,21,23-26]$, soft drinks consumption, physical education at school $[15,20,22]$, psychological distress $[15,20,22,23]$, being bullied $[2,18,19,23]$, engaging in physical fight $[2$, $18,19,25]$, truancy [14,20,22,25], ever had sex [20,21], depression [14], loneliness [14,24,25], and parental or guardian support and bonding [20,22] are associated with unintentional injuries among adolescents.

In Ghana, there is a general dearth of literature on adolescents' injuries. A retrospective descriptive study by Morna et al. [27] reported 17.6\% of injury-related deaths from 2012-2018 among children aged 16 years and below at the Cape Coast Teaching Hospital (Cape Coast, Ghana). Another study conducted in the Korle-Bu Teaching Hospital (Accra, Ghana), showed that injury-related deaths accounted for $17 \%$ of all autopsies performed on adolescents (10-19 years) between 2001 and 2003 [28]. Road traffic injuries and drowning were the most reported cause of injury-related mortalities in both studies $[27,28]$. 
Due to the burden of unintentional injuries among adolescents, there is the need to understand the country-specific nature and distribution of these injuries to better inform educational campaigns, evidence-based planning, priority settings, and resource allocation for its prevention and control [1,29]. Hence, this study seeks to determine the prevalence and factors influencing unintentional injuries among in-school adolescents using nationally representative data.

\section{Materials and Methods}

\subsection{Study Design and Sampling Technique}

Data for this study were obtained from the 2012 Global School-Based Health Survey (GSHS) of Ghana [30]. The 2012 GSHS of Ghana was conducted in the country among adolescents with partnership from the World Health Organization (WHO), Center for Disease Control and Prevention (CDC, Atlanta, GA, USA), Middle Tennessee University (Murfreesboro, TN, USA), and Ghana Education Service (GES, Accra, Ghana). The survey data were collected using a cross-sectional study design from WHO countries. Closeended structured questionnaires were used to collect the data from the students. The students self-reported their responses to each question on a computer scannable answer sheet. Generally, the GSHS survey measures behavioral risk and protective factors among adolescents which has a propensity of causing morbidity and mortality in youths and adults. These factors include; alcohol and other drug use, dietary behaviors, hygiene, mental health, physical activity, protective factors, sexual behavior, tobacco use, violence, and unintentional injury [31].

The study participants were recruited from junior and senior high schools in all the administrative regions in Ghana (then 10 regions). A two-stage cluster sampling technique was used in selecting the schools and students, respectively. At the initial stage, the study schools were selected with probability proportional to the school's enrolment size. At the last stage, classes within chosen schools were randomly selected, and all the students in the sampled classrooms were eligible to participate in the survey. However, the survey included students who were aged 10 to 19 years (period of adolescence), present at school on the day of data collection, and showed evidence of written informed consent (those aged 18 years and above), and written parental or guardian consent form and child assent form (those between 18 years). This sampling method ensured that every eligible student had an equal chance of being selected for inclusion in the study. Numerical weights were applied to each student's record to enable the generalization of results to in-school adolescents. A total of 3632 students from junior and senior high schools participated in the survey. Of this, 1648 and 1984 students were from junior and senior high schools, respectively. Among the junior high schools (JHS), the school, student, and overall response rates were $100 \%, 82 \%$, and $82 \%$, respectively. Similarly, that of the senior high schools (SHS) was $96 \%, 74 \%$, and 71\%. However, 2058 students with complete cases on all selected variables were used as the sample for the current study. The dataset is available freely at https:/ /www.who.int/ncds/surveillance/gshs/ghanadataset/en/ (accessed on 1 February2020). We relied on the "Strengthening the Reporting of Observational Studies in Epidemiology" (STROBE) statement in writing the manuscript [32].

\subsection{Study Variables}

\subsubsection{Outcome Variable}

The main outcome variable was self-reported injury. This was assessed using the question "During the past 12 months, how many times were you seriously injured?" A total of eight responses were provided ranging from $1=0$ times through to $8=12$ or more times. A response of " 0 times" means the absence of injury in the previous 12 months, while responses from 1 to 12 or more showed that the student had sustained one or more serious injuries. Serious injury was defined as when it makes you miss at least one full day of usual activities (such as school, sports, or a job) or requires treatment by a doctor or 
nurse. Additional two questions addressing the type and cause of serious injury were also assessed. Detailed questions, responses, and coding can be found in Table 1.

\subsubsection{Explanatory Variables}

Independent variables used to determine the predictors of one or more serious injuries were sociodemographic characteristics (age, sex, grade), hunger (a proxy to socio-economic status), substance use (current alcohol use, smoking cigarettes, tobacco use, marijuana use, drugs use), peer support, psychological distress, and parental or guardian support and bonding. The explanatory variables were selected based on findings from previous studies [20-23,33]. Psychological distress was assessed using five items (loneliness, anxiety, suicidal ideation, suicidal attempt, and close friends). All five items were summed. The summed items were grouped into " $0=0$ " low; " $1=1$ " medium and " $2-5$ " $=3$ high. The same process was repeated for parental or guardian support and bonding. An index was created by summing all four items. The index created was grouped into " $0-1$ " $=$ low; " 2 " = medium; and " $3-4$ " = high. Psychological distress and parental or guardian support and bonding were classified per previous similar studies $[20,22,23]$. The specific variables, sample questions, responses, and coding can be found in Table 1.

\subsection{Statistical Analyses}

Data analyses were carried out using Stata software version 16.0 (Stata Corporation, College Station, TX, USA). The dataset was cleaned and recoded before the final analysis. Missing data on the variables of interest were not included in the analysis. All the recoded variables in this study were referred to other studies that used GSHS data [20-23,33]. Two-level analysis using descriptive and inferential statistics was performed. Firstly, descriptive statistics employing frequencies, percentages, and confidence intervals were done to determine the prevalence of injury, types of injury, and causes of injury. Lastly, binary logistic regression was used to determine the independent predictors of injury. Two binary logistic regression models (bivariate and multivariable) were built with the first model showing the independent association between each of the explanatory variables and the outcome variable, while the second model looked at the joint association between all the explanatory variables and injured once or multiple times. In the bivariate model, due to multiple-testing, we introduced a correction method by using the Bonferroni correction method. This was done by dividing the alpha rate $(p=0.05)$ by the number of analysis performed (17 explanatory variables). Thus, $0.05 / 17=0.0029$. Therefore, at the bivariate analysis, statistical significance was declared at $p<0.003$. However, to avoid the assumption that a variable that is not significant at the bivariate level will not be significant at the multivariable level, we included all variables in the multivariable model, irrespective of their significance at the bivariate level of the regression analysis. The results of the logistic regression were presented using crude and adjusted odds ratios and their respective $95 \%$ confidence intervals signifying the level of precision. We checked for multicollinearity with Variance Inflation Factor (VIF). We found a mean VIF of 1.52 showing that there was no evidence of multicollinearity among the variables. A $p$-value of less than $5 \%$ or 0.05 was considered significant. Complex sample analysis (svy) and the inherent sample weight were applied in all analyses to reduce bias from non-response and improve generalizability to all in-school adolescents in Ghana. The reference categories for all the explanatory variables were based on previous studies that used the GSHS dataset [20-23]. 
Table 1. Study variables.

\begin{tabular}{|c|c|c|}
\hline Variables & Question & Response Options and Recoding \\
\hline \multicolumn{3}{|c|}{ Outcome variable } \\
\hline Injury & $\begin{array}{l}\text { During the past } 12 \text { months, how many } \\
\text { times were you seriously injured? }\end{array}$ & $\begin{array}{l}1=0 \text { times; to } 8=12 \text { or more time } \\
\quad(\text { coded as } \mathbf{1}=\mathbf{0} ; \mathbf{2}-\mathbf{8}=\mathbf{1})\end{array}$ \\
\hline \multicolumn{3}{|c|}{ Injury events } \\
\hline Type of injury & $\begin{array}{l}\text { During the past } 12 \text { months, what was } \\
\text { the most serious injury that happened } \\
\text { to you? }\end{array}$ & $\begin{array}{l}\text { 1. I was not seriously injured during the past } 12 \text { months } \\
\text { 2. I had a broken bone or a dislocated joint } \\
\text { 3. I had a cut or stab wound } \\
\text { 4. I had a concussion or other head or neck injury was } \\
\text { 5. I had a gunshot wound } \\
\text { 6. I had a bad burn } \\
\text { 7. I was poisoned or took too much of a drug } \\
\text { 8. Something else happened to me }\end{array}$ \\
\hline Cause of injury & $\begin{array}{l}\text { During the past } 12 \text { months, what was } \\
\text { the major cause of the most serious } \\
\text { injury that happened to you? }\end{array}$ & $\begin{array}{l}\text { 1. I was not seriously injured during the past } 12 \text { months } \\
\text { 2. I was in a motor vehicle accident or hit by a motor } \\
\text { 3. I fehicle } \\
\text { 4. Something fell on me or hit me } \\
\text { 5. I was attacked or abused or was fighting with someone } \\
\text { 6. I was in a fire or too near a flame or something hot } \\
\text { 7. I inhaled or swallowed something bad for me } \\
\text { 8. Something else caused my injury }\end{array}$ \\
\hline
\end{tabular}

\section{Explanatory variables}

\begin{tabular}{|c|c|c|}
\hline Age & How old are you? & $\begin{array}{l}1=11 \text { years or younger; to } 8=18 \text { years or older } \\
\quad(\text { coded as } \mathbf{1}-\mathbf{3}=\mathbf{0} ; \mathbf{4}-\mathbf{6}=\mathbf{1} ; \mathbf{7}-\mathbf{8}=\mathbf{2})\end{array}$ \\
\hline Sex & What is your sex? & $\begin{array}{c}1=\text { male, } 2=\text { female } \\
(\text { coded as } \mathbf{2}=\mathbf{0} \text {; and } \mathbf{1}=\mathbf{1})\end{array}$ \\
\hline Grade & In what grade are you? & Coded as $\mathrm{JHS}=0 ;$ and $\mathrm{SHS}=1$ \\
\hline Physical education & $\begin{array}{l}\text { During this school year, on how many } \\
\text { days did you go to physical education } \\
\text { (PE) class each week? }\end{array}$ & $\begin{aligned} 1= & 0 \text { days; to } 6=5 \text { or more days } \\
& (\text { coded } \mathbf{1}=\mathbf{0} \text { and } 2-6=1)\end{aligned}$ \\
\hline Truancy & $\begin{array}{l}\text { During the past } 30 \text { days, on how many } \\
\text { days did you miss classes or school } \\
\text { without permission? }\end{array}$ & $\begin{array}{l}1=0 \text { days; to } 5=10 \text { or more } \\
(\text { coded } \mathbf{1}=\mathbf{0} \text { and } \mathbf{2}-\mathbf{5}=\mathbf{1})\end{array}$ \\
\hline $\begin{array}{l}\text { Hunger (a proxy of } \\
\text { socioeconomic status) }\end{array}$ & $\begin{array}{l}\text { During the past } 30 \text { days, how often did } \\
\text { you go hungry because there was no } \\
\text { enough food in your home? }\end{array}$ & $\begin{array}{l}1=\text { never; to } 5=\text { always } \\
(\text { coded } \mathbf{1}-\mathbf{3}=\mathbf{0}, \mathbf{4}-\mathbf{5}=\mathbf{1})\end{array}$ \\
\hline Bullied & $\begin{array}{l}\text { During the past } 30 \text { days, on how many } \\
\text { days were you bullied? }\end{array}$ & $\begin{aligned} 1= & 0 \text { days; to } 7=\text { All } 30 \text { days } \\
& (\text { coded } \mathbf{1}=\mathbf{0} ; \mathbf{2}-\mathbf{7}=\mathbf{1})\end{aligned}$ \\
\hline Physical fight & $\begin{array}{l}\text { During the past } 12 \text { months, how many } \\
\text { times were you in a physical fight? }\end{array}$ & $\begin{array}{l}1=0 \text { times; to } 8=12 \text { or more times } \\
\quad(\text { coded } \mathbf{1}=\mathbf{0} \text { and } \mathbf{2}-\mathbf{8}=\mathbf{1})\end{array}$ \\
\hline Physically attacked & $\begin{array}{l}\text { During the past } 12 \text { months, how many } \\
\text { times were you physically attacked? }\end{array}$ & $\begin{array}{l}1=0 \text { times; to } 8=12 \text { or more times } \\
\quad(\text { coded } \mathbf{1}=\mathbf{0} \text { and } \mathbf{2}-\mathbf{8}=\mathbf{1})\end{array}$ \\
\hline Peer support & $\begin{array}{l}\text { During the past } 30 \text { days, how often } \\
\text { were most of the students in your } \\
\text { school kind and helpful? }\end{array}$ & $\begin{array}{l}1=\text { never; to } 5=\text { always } \\
(\text { coded } \mathbf{1}-\mathbf{3}=\mathbf{0} \text { and } \mathbf{4}-\mathbf{5}=\mathbf{1})\end{array}$ \\
\hline
\end{tabular}


Table 1. Cont.

\begin{tabular}{|c|c|c|}
\hline Variables & Question & Response Options and Recoding \\
\hline \multicolumn{3}{|c|}{ Substance use } \\
\hline Current alcohol use & $\begin{array}{l}\text { During the past } 30 \text { days, on how many } \\
\text { days did you have at least one drink } \\
\text { containing alcohol? }\end{array}$ & $\begin{array}{l}1=0 \text { days; to } 7=\text { All } 30 \text { days } \\
\quad(\text { coded as } 1=0 ; 2-7=1)\end{array}$ \\
\hline Current tobacco use & $\begin{array}{l}\text { During the past } 30 \text { days, on how many } \\
\text { days did you use any tobacco products } \\
\text { other than cigarettes, such as tawa snuff } \\
\text { powder, chewing tobacco, paper rolled } \\
\text { tobacco, dip, cigar, or pipe? }\end{array}$ & $\begin{array}{l}1=0 \text { days; to } 7=\text { All } 30 \text { days } \\
\text { (coded as } \mathbf{1}=\mathbf{0} \text { and } 2-7=\mathbf{1} \text { ) }\end{array}$ \\
\hline $\begin{array}{l}\text { Current cigarettes use } \\
\text { (current smoking) }\end{array}$ & $\begin{array}{l}\text { During the past } 30 \text { days, how many } \\
\text { days did you smoke cigarettes? }\end{array}$ & $\begin{array}{l}1=0 \text { days; to } 7=\text { All } 30 \text { days } \\
\text { (coded as } \mathbf{1}=\mathbf{0} \text { and } \mathbf{2}-7=\mathbf{1} \text { ) }\end{array}$ \\
\hline Current marijuana use & $\begin{array}{l}\text { During the past } 30 \text { days, how many } \\
\text { times have you used marijuana (also } \\
\text { called wee, Jah, Indian hemp, } \\
\text { ahabammono, and ganja)? }\end{array}$ & $\begin{aligned} 1= & 0 \text { times; to } 5=20 \text { or more times } \\
& \quad(\text { coded as } \mathbf{1}=\mathbf{0} \text { and } \mathbf{2}-\mathbf{5}=\mathbf{1})\end{aligned}$ \\
\hline Drug use & $\begin{array}{c}\text { During your life, how many times have } \\
\text { you used amphetamines or } \\
\text { methamphetamines (also called ice } \\
\text { or yellow)? }\end{array}$ & $\begin{aligned} 1= & 0 \text { times; to } 5=20 \text { or more times } \\
& \quad(\text { coded as } \mathbf{1}=\mathbf{0} \text { and } \mathbf{2}-\mathbf{5}=\mathbf{1})\end{aligned}$ \\
\hline \multicolumn{3}{|c|}{ Psychological distress } \\
\hline Loneliness & $\begin{array}{l}\text { During the past } 12 \text { months, how often } \\
\text { have you felt lonely? }\end{array}$ & $\begin{aligned} 1=\text { never, } 2= & \text { rarely, } 3=\text { sometimes, } 4=\text { most of the time to } \\
5=\text { always } & \\
& \text { (coded as } \mathbf{1}-\mathbf{3}=\mathbf{0} \text { and } \mathbf{4}-\mathbf{5}=\mathbf{1} \text { ) }\end{aligned}$ \\
\hline Anxiety & $\begin{array}{c}\text { During the past } 12 \text { months, how often } \\
\text { have you been so worried about } \\
\text { something that you could not sleep } \\
\text { at night? }\end{array}$ & $\begin{array}{l}1=\text { never to } 5=\text { always } \\
(\text { coded } 1-3=0 \text { and } 4-5=1 \text { ) }\end{array}$ \\
\hline Suicide attempt & $\begin{array}{l}\text { During the past } 12 \text { months, how many } \\
\text { times did you actually attempt suicide? }\end{array}$ & $\begin{array}{c}1=\text { yes, } 2=\text { no } \\
\text { (coded as } \mathbf{2}=\mathbf{0} \text {; and } \mathbf{1}=\mathbf{1} \text { ) }\end{array}$ \\
\hline Close friends & How many close friends do you have? & $\begin{array}{c}1=0 ; \text { to } 4=3 \text { or more } \\
\text { (coded as } \mathbf{1}=\mathbf{1} ; \text { and } \mathbf{2}-\mathbf{4}=\mathbf{0} \text { ) }\end{array}$ \\
\hline \multicolumn{3}{|c|}{ Parental or guardian support } \\
\hline Parental supervision & $\begin{array}{l}\text { During the past } 30 \text { days, how often did } \\
\text { your parents or guardians check to see } \\
\text { if your homework was done? }\end{array}$ & $\begin{array}{l}1=\text { never; to } 5=\text { always } \\
(\text { coded } 1-3=0 ; 4-5=1)\end{array}$ \\
\hline Parental Connectedness & $\begin{array}{l}\text { During the past } 30 \text { days, how often did } \\
\text { your parents or guardians understand } \\
\text { your problems and worries? }\end{array}$ & $\begin{array}{l}1=\text { never; to } 5=\text { always } \\
(\text { coded } 1-3=0 ; 4-5=1)\end{array}$ \\
\hline $\begin{array}{l}\text { Parental or guardian } \\
\text { Bonding }\end{array}$ & $\begin{array}{c}\text { During the past } 30 \text { days, how often did } \\
\text { your parents or guardians really know } \\
\text { what you were doing with your } \\
\text { free time? }\end{array}$ & $\begin{array}{l}1=\text { never; to } 5=\text { always } \\
(\text { coded } 1-3=0 ; 4-5=1)\end{array}$ \\
\hline $\begin{array}{l}\text { Parental respect for } \\
\text { privacy }\end{array}$ & $\begin{array}{l}\text { During the past } 30 \text { days, how often did } \\
\text { your parents or guardians go through } \\
\text { your things without your approval? }\end{array}$ & $\begin{array}{l}1=\text { never; to } 5=\text { alwayss } \\
(\text { coded } 1-3=0 \text { and } 4-5=2)\end{array}$ \\
\hline
\end{tabular}

\subsection{Ethical Consideration}

Ethics approval was not required for this study since the data is secondary and is available in the public domain. However, the survey was approved by the Institutional Review Board at Middle Tennessee State University. Before the conduct of the survey, institutional permission to carry out the study was sought from the GES. All the GES's 
ethical guidelines and policies concerning the use of students were strictly adhered to. Written informed consent to participate in the study was obtained from school managers and students aged 18 years and above. Parental consent and child assent were sought from students below 18 years. Students anonymously and voluntarily completed the questionnaire.

\section{Results}

\subsection{Prevalence of Injury and Background Characteristics of Respondents}

Of the 2058 in-school adolescents considered for the analysis, $56.3 \%$ were males. The majority $(51.5 \%)$ were aged 17 years or older. Most $(61.2 \%)$ of the students were in SHS. The overall prevalence of once or multiple times of serious injuries was $57.0 \%$ (55.7\% among males and $58.7 \%$ among females). Over sixty-six percent of the students in JHS reported having been injured, while $63.1 \%$ of students aged $14-16$ years were injured. Among those who reported having been injured once or multiple times, hunger, physical education, truancy, physical fighting, physical attack and peer support contributed to $63.9 \%, 73.8 \%$, $67.9 \%, 72.8 \%, 75.9 \%, 75.4 \%$ and $53.4 \%$ of the prevalence, respectively. Current alcohol use $(73.1 \%)$, current marijuana use $(94.4 \%)$, smoking cigarette $(84.1 \%)$, tobacco use $(82.2 \%)$, drug use (91.0\%), high psychological distress (74.3\%), and high parental support (54.3\%) were reported among students who were injured once or multiple times (see Table 2).

Table 2. Sample background characteristics and prevalence of injuries.

\begin{tabular}{|c|c|c|c|c|}
\hline \multicolumn{5}{|c|}{ Injured Once or Multiple Times $n=2058$} \\
\hline Variable & Frequency & Percentage & Yes (\%) & No $(\%)$ \\
\hline $\begin{array}{c}\text { Injured Once or Multiple } \\
\text { Times }\end{array}$ & & & 57.0 & 43.0 \\
\hline \multicolumn{5}{|l|}{$\begin{array}{l}\text { Times } \\
\text { Sex }\end{array}$} \\
\hline Female & 900 & 43.7 & 58.7 & 41.3 \\
\hline Male & 1158 & 56.3 & 55.7 & 44.2 \\
\hline \multicolumn{5}{|l|}{ Age } \\
\hline 13 years or younger & 240 & 11.7 & 62.5 & 37.5 \\
\hline $14-16$ years & 758 & 36.8 & 63.1 & 36.9 \\
\hline 17 years or older & 1060 & 51.5 & 51.5 & 48.5 \\
\hline \multicolumn{5}{|l|}{ School } \\
\hline JHS & 798 & 38.8 & 66.8 & 33.2 \\
\hline SHS & 1260 & 61.2 & 50.9 & 49.1 \\
\hline \multicolumn{5}{|l|}{ Hunger } \\
\hline No & 1806 & 87.8 & 56.1 & 43.9 \\
\hline Yes & 252 & 12.2 & 63.9 & 36.1 \\
\hline \multicolumn{5}{|l|}{ Physical education } \\
\hline No & 604 & 29.3 & 66.5 & 33.5 \\
\hline Yes & 1454 & 70.7 & 73.8 & 26.2 \\
\hline \multicolumn{5}{|l|}{ Truancy } \\
\hline No & 1363 & 66.2 & 51.5 & 48.5 \\
\hline Yes & 695 & 33.8 & 67.9 & 32.1 \\
\hline \multicolumn{5}{|l|}{ Bullied } \\
\hline No & 1114 & 54.1 & 43.7 & 56.3 \\
\hline Yes & 944 & 45.9 & 72.8 & 27.2 \\
\hline \multicolumn{5}{|l|}{ Physical attack } \\
\hline No & 1262 & 61.3 & 45.5 & 54.5 \\
\hline Yes & 796 & 38.7 & 75.4 & 24.6 \\
\hline \multicolumn{5}{|l|}{ Physical fight } \\
\hline No & 1353 & 65.7 & 47.2 & 52.8 \\
\hline Yes & 705 & 34.3 & 75.9 & 24.1 \\
\hline \multicolumn{5}{|l|}{ Peer support } \\
\hline No & 1374 & 66.8 & 58.9 & 41.1 \\
\hline Yes & 684 & 33.2 & 53.4 & 46.6 \\
\hline
\end{tabular}


Table 2. Cont.

\begin{tabular}{|c|c|c|c|c|}
\hline \multicolumn{5}{|c|}{ Injured Once or Multiple Times $n=2058$} \\
\hline Variable & Frequency & Percentage & Yes $(\%)$ & No $(\%)$ \\
\hline \multicolumn{5}{|l|}{ Alcohol use } \\
\hline No & 1813 & 88.1 & 54.9 & 45.1 \\
\hline Yes & 245 & 11.9 & 73.1 & 26.9 \\
\hline \multicolumn{5}{|c|}{ Smoking cigarette } \\
\hline No & 1970 & 95.7 & 55.8 & 44.2 \\
\hline Yes & 88 & 4.3 & 84.1 & 15.9 \\
\hline \multicolumn{5}{|c|}{ Marijuana use } \\
\hline No & 1987 & 96.6 & 55.7 & 44.3 \\
\hline Yes & 71 & 3.4 & 94.4 & 5.6 \\
\hline \multicolumn{5}{|c|}{ Tobacco use } \\
\hline No & 1923 & 93.4 & 55.3 & 44.7 \\
\hline Yes & 135 & 6.6 & 82.2 & 17.8 \\
\hline \multicolumn{5}{|l|}{ Drug use } \\
\hline No & 1958 & 95.1 & 55.3 & 44.7 \\
\hline Yes & 100 & 4.9 & 91.0 & 9.0 \\
\hline \multicolumn{5}{|c|}{ Psychological distress } \\
\hline Low & 1124 & 54.6 & 50.1 & 49.9 \\
\hline Medium & 495 & 24.1 & 57.6 & 42.4 \\
\hline High & 439 & 21.3 & 74.3 & 25.7 \\
\hline \multicolumn{5}{|c|}{ Parental or guardian support } \\
\hline Low & 1173 & 57.0 & 58.4 & 41.6 \\
\hline Medium & 447 & 21.7 & 56.2 & 43.8 \\
\hline High & 438 & 21.3 & 54.3 & 45.7 \\
\hline
\end{tabular}

$\overline{\mathrm{JHS}}=$ junior high school, SHS = senior high school.

\subsection{Prevalence of Injury Events among the Respondents}

Regarding the injury events, the majority (15.2\%) of the adolescents reported: "I had a cut or stab wound" as the leading type of injury, followed by a broken bone or dislocated joint (10.6\%), concussion or head injury (3.7\%), and "I had a burn" $(2.4 \%)$. Adolescents who reported "I had a gunshot" and "I was poisoned" recorded $0.9 \%$ each. Boys reported slightly more types of serious injuries compared to girls in "I had a cut or stab wound", a broken bone or dislocated joint, and "I had a gunshot". Most reported causes of serious injury were "I fell" (13.1\%), "something fell on me or hit me" (8.7\%), motor vehicle accidents, "I was attacked" (2.9\%), "Was in a fire" $(2.4 \%)$, and "breathed something bad" (1.8\%) (see Table 3).

\subsection{Association between Injured Once or Multiple Times and Explanatory Variables}

Table 4 shows the logistic regression model on the association between background characteristics and experience of injury (injured once or multiple times). At the adjusted stage, students aged $14-16(\mathrm{aOR}=1.60, \mathrm{CI}=1.12-2.28)$; students who participated in physical education $(\mathrm{aOR}=1.27, \mathrm{CI}=1.03-1.58)$; those who were truant at school $(\mathrm{aOR}=$ $1.42, \mathrm{CI}=1.14-1.77)$; those who were bullied ( $\mathrm{aOR}=2.16, \mathrm{CI}=1.75-2.65)$; being physically attacked $(\mathrm{aOR}=2.21, \mathrm{CI}=1.78-2.75)$; those who engaged in physical fight $(\mathrm{aOR}=1.94, \mathrm{CI}$ $=1.54-2.45)$, and those with high psychological distress $(\mathrm{aOR}=2.00, \mathrm{CI}=1.52-2.63)$ were more likely to be injured once or multiple times. Students from SHS were 39\% less likely to be injured once or multiple times ( $\mathrm{aOR}=0.61, \mathrm{CI}=0.47-0.79$ ) compared to those in JHS. 
Table 3. Prevalence of injury events by sex.

\begin{tabular}{cccc}
\hline Variable & Total (\%) (CI) & Boys (\%) (CI) & Girls (\%) (CI) \\
\hline Type of injury & & & \\
Broken bone or dislocated joint & $10.6(9.3,12.0)$ & $11.6(9.8,13.6)$ & $9.3(7.5,11.4)$ \\
I had a cut or stab wound & $15.2(13.7,16.8)$ & $16.8(14.7,19.1)$ & $13.1(11.0,15.5)$ \\
Concussion/head injury & $3.7(2.9,4.7)$ & $3.1(2.2,4.3)$ & $4.6(3.3,6.1)$ \\
I had a gunshot wound & $0.9(0.6,1.4)$ & $1.1(0.6,1.9)$ & $0.7(0.2,1.4)$ \\
I had a burn & $2.4(1.8,3.2)$ & $1.6(1.0,2.6)$ & $3.4(2.4,4.9)$ \\
I was poisoned & $0.9(0.5,1.4)$ & $0.7(0.3,1.4)$ & $1.1(0.5,2.0)$ \\
Something else happened to me & $11.7(10.3,13.1)$ & $9.4(7.8,11.2)$ & $14.5(12.3,17.0)$ \\
Cause of injury & & & \\
Motor vehicle accidents & $5.5(4.5,6.6)$ & $7.0(5.6,8.6)$ & $3.6(2.4,5.0)$ \\
I fell & $13.1(11.6,14.6)$ & $12.4(10.6,14.5)$ & $13.9(11.7,16.3)$ \\
Something fell on me or hit me & $8.7(7.6,10.1)$ & $8.8(7.2,10.6)$ & $8.7(6.9,10.7)$ \\
I was attacked & $2.9(2.2,3.7)$ & $2.8(2.0,4.0)$ & $3.0(2.0,4.3)$ \\
Was in a fire & $2.4(1.8,3.1)$ & $1.6(0.9,2.4)$ & $3.4(2.4,4.9)$ \\
Breathed something bad & $1.8(1.3,2.5)$ & $1.3(0.7,2.1)$ & $2.4(1.5,3.7)$ \\
Something else & $11.2(9.8,12.7)$ & $10.0(8.3,11.9)$ & $12.8(10.7,15.1)$ \\
\hline
\end{tabular}

$\overline{\mathrm{CI}}=$ Confidence Interval.

Table 4. Binary logistic regression analysis of predictors of unintentional injury.

\begin{tabular}{|c|c|c|}
\hline \multirow[b]{2}{*}{ Variable } & \multicolumn{2}{|c|}{ One or More Injuries } \\
\hline & COR $(95 \%$ CI $) p$-Value & AOR $(95 \%$ CI) $p$-Value \\
\hline \multicolumn{3}{|l|}{ Sex } \\
\hline Female & 1.0 & 1.0 \\
\hline Male & $0.89(0.75,1.06) 0.190$ & $0.94(0.77,1.14) 0.525$ \\
\hline \multicolumn{3}{|c|}{ 然 } \\
\hline 13 years or younger & 1.0 & 1.0 \\
\hline $14-16$ years & $1.02(0.76,1.38) 0.875$ & $1.60(1.12,2.28) 0.009$ \\
\hline 17 years or older & $0.64(0.48,0.85) 0.002$ & $1.43(0.96,2.13) 0.074$ \\
\hline \multicolumn{3}{|l|}{ School } \\
\hline JHS & 1.0 & 1.0 \\
\hline SHS & $0.51(0.43,0.62)<0.001$ & $0.61(0.47,0.79)<0.001$ \\
\hline \multicolumn{3}{|l|}{ Hunger } \\
\hline No & 1.0 & 1.0 \\
\hline Yes & $1.38(1.05,1.82) 0.020$ & $1.14(0.83,1.55) 0.416$ \\
\hline \multicolumn{3}{|l|}{ Physical education } \\
\hline No & 1.0 & 1.0 \\
\hline Yes & $1.42(1.17,1.71)<0.001$ & $1.27(1.03,1.58) 0.026$ \\
\hline \multicolumn{3}{|l|}{ Truancy } \\
\hline No & 1.0 & 1.0 \\
\hline Yes & $1.99(1.65,2.41)<0.001$ & $1.42(1.14,1.77) 0.002$ \\
\hline \multicolumn{3}{|l|}{ Bullied } \\
\hline No & 1.0 & 1.0 \\
\hline Yes & $3.44(2.86,4.14)<0.001$ & $2.16(1.75,2.65)<0.001$ \\
\hline \multicolumn{3}{|l|}{ Physical attack } \\
\hline No & 1.0 & 1.0 \\
\hline Yes & $3.67(3.02,4.46)<0.001$ & $2.21(1.78,2.75)<0.001$ \\
\hline \multicolumn{3}{|l|}{ Physical fight } \\
\hline No & 1.0 & 1.0 \\
\hline Yes & $3.52(2.87,4.31)<0.001$ & $1.94(1.54,2.45)<0.001$ \\
\hline \multicolumn{3}{|l|}{ Peer support } \\
\hline No & 1.0 & 1.0 \\
\hline Yes & $0.80(0.66,0.96) 0.017$ & $0.94(0.75,1.17) 0.568$ \\
\hline \multicolumn{3}{|l|}{ Current alcohol use } \\
\hline No & 1.0 & 1.0 \\
\hline Yes & $2.23(1.66,3.00)<0.001$ & $1.11(0.78,1.58) 0.562$ \\
\hline
\end{tabular}


Table 4. Cont.

\begin{tabular}{|c|c|c|}
\hline \multirow[b]{2}{*}{ Variable } & \multicolumn{2}{|c|}{ One or More Injuries } \\
\hline & COR $(95 \%$ CI $) p$-Value & AOR $(95 \%$ CI $) p$-Value \\
\hline \multicolumn{3}{|c|}{ Current smoking cigarette } \\
\hline $\mathrm{No}$ & 1.0 & 1.0 \\
\hline Yes & $4.18(2.34,7.45)<0.001$ & $0.75(0.35,1.61) 0.466$ \\
\hline \multicolumn{3}{|c|}{ Current marijuana use } \\
\hline No & 1.0 & 1.0 \\
\hline Yes & $13.32(4.84,36.66)<0.001$ & $3.08(0.93,10.26) 0.067$ \\
\hline \multicolumn{3}{|c|}{ Current tobacco use } \\
\hline No & 1.0 & 1.0 \\
\hline Yes & $3.74(2.39,5.87)<0.001$ & $1.21(0.69,2.13) 0.501$ \\
\hline \multicolumn{3}{|l|}{ Drug use } \\
\hline No & 1.0 & 1.0 \\
\hline Yes & $8.17(4.09,16.30)<0.001$ & $2.08(0.93,4.66) 0.074$ \\
\hline \multicolumn{3}{|c|}{ Psychological distress } \\
\hline Low & 1.0 & 1.0 \\
\hline Medium & $1.35(1.09,1.67) 0.006$ & $1.14(0.90,1.45) 0.278$ \\
\hline High & $2.87(2.25,3.67)<0.001$ & $2.00(1.52,2.63)<0.001$ \\
\hline \multicolumn{3}{|c|}{ Parental or guardian support } \\
\hline Low & 1.0 & 1.0 \\
\hline Medium & $0.91(0.73,1.14) 0.414$ & $0.81(0.71,1.17) 0.477$ \\
\hline High & $0.84(0.68,1.06) 0.143$ & $0.97(0.75,1.26) 0.850$ \\
\hline
\end{tabular}

\section{Discussion}

This study sought to determine the prevalence and factors influencing unintentional injuries among in-school adolescents in Ghana. The prevalence of injury (injured once or multiple times) among adolescents in Ghana was $57.0 \%$. This finding is similar to that of Mozambique [15] and Jamaica [12], which reported 55.7\% and 59.5\%, respectively. The present finding is higher than the overall prevalence from studies conducted in Malaysia [20], and among four Southeast Asian countries (Indonesia, Myanmar, Sri Lanka, and Thailand) [23]. All the studies reported prevalence rates below fifty percent. However, higher rates were found in Egypt (68.5\%) [33] Djibouti (61.1\%) [2], 65.8\% in Botswana [16], and 70\% in Timor-Leste [24]. Additionally, our finding on the prevalence of unintended injuries was lower compared to that of Pelzter [14], who reported a $68.2 \%$ prevalence of one or multiple injuries among adolescents from six African countries. Differences in school settings and external environmental factors could explain the observed differences in the prevalence rates.

In the current study, the most reported causes of serious injuries were; fall, hit by an object or something, and motor vehicle accidents, while the majority reported cut or stab wound, a broken bone or dislocated joint, and head injury or concussion as the frequent type of serious injury. Similar findings have been reported in other GSHS studies [13,15,20,22-24].

Adolescents aged 14-16 years were more likely to report serious injuries compared to the younger age group. Though unintentional injuries are prevalent across an individual's lifespan, adolescents in this age group (14-16 years) could have encountered risks that might be different from other age groups [34]. Additionally, varied behavioral, physical, and cognitive abilities, coupled with curiosity and impulsivity, could account for the observed association [34]. A consistent finding was reported in a study conducted in Spain [35].

SHS students were less likely to report being injured once or multiple times. This finding concurs with a study conducted in China [36]. Another study by Albashtawy et al. [37] reported that students in the lower level, thus grade 7, were more likely to report being injured compared to those of higher levels. Adolescents in higher levels could be experiencing variations in growth and development stages and changes in their activities and playing patterns, which could have contributed to low injury prevalence 
among them [37]. Additionally, poor individual safety awareness and adventure and impulsiveness inherent in younger students with poor self-restraint could explain the observed association in the present study [36].

Being truant at school was found to increase the odds of injury among adolescents. Consistent findings have been reported by other researchers using GSHS data in Egypt [33], Malaysia [20], and Botswana [16]. A possible explanation for the observed association could be that truant adolescents are more likely to engage in behaviors (such as violence, illegal road behaviors, drugs, and alcohol use) that contribute to the likelihood of an injury [24].

Consistent with other studies conducted among adolescents $[15,20,22,26]$, the present study reported that participating in physical education at school was associated with higher odds of one or multiple injuries. As explained by Carmeli et al. [38], lack of sufficient warm-up, poor playing grounds, unsuitable outfits, lack of safety precautions, and high extraneous exercises that have a high mechanical impact could account for the reported injuries among students who partake in physical education.

Adolescent aggressive behaviors: bullying, physical fight, and physical attack were all associated with higher odds of serious injury in the present study. Researchers posited that an adolescent exhibiting one form of aggressive behavior could be a response or reaction to other violent conduct towards him or her. For instance, Jansen et al. [19] stipulated that being a victim or perpetrator of bullying is associated with a greater tendency to engage in a physical fight, which can cause an injury that requires medical treatment. Other studies in the Philippines and five ASEAN countries reported that adolescents who were bullied were more likely to engage in a physical fight $[39,40]$. Another study among adolescents in seven Caribbean countries concluded that being in a physical fight was associated with risky behaviors such as being bullied [41]. The association between being bullied, engaged in a physical fight, and being physically attacked and injury occurrence have been reported by scholars from other studies [11,13,14,18-20].

The study found high psychological distress as contributing to the increase in the likelihood of injury among adolescents. Psychological distress may have poorly affected the adolescents' physical and mental health making them susceptible to undertaking risky behaviors with injury being the most likely consequence [13]. The association in the present study is in line with those of previous studies $[15,20,22]$.

\section{Limitations of the Study}

The cross-sectional nature of the dataset used is not appropriate to establish any causal inferences from the results obtained. Recall bias is another limitation. The self-reported nature of the questions could be subjected to social desirability and non-response biases. The study involved only in-schooladolescents. Hence, the findings cannot be generalized to the entire adolescent population. The exclusion of missing cases from the dataset before analysis led to the reduction in sample size which could have impacted on the results of the study. Additionally, the analysis was based on the risk factors found in the dataset, while other potential factors that can influence injury occurrence were not assessed. Additionally, there was possible underreporting of injuries as data were not collected from students who were absent on the day of data collection. The data used for the analysis was nine years old and does not present the current situation of unintended injuries among in-school adolescents in Ghana. However, the findings of our paper can guide in developing current interventions to deal with unintended injuries among in-school adolescents in the country.

\section{Conclusions}

A relatively high prevalence of injury occurrence was found in the present study. Factors that were associated with an increased likelihood of injury among the adolescents were being aged 14-16 years, being bullied, participating in physical education at school, being involved in a physical fight, being truant at school, being physically attacked, and having high psychological distress. Adolescents from SHS were less likely to be injured. 
There is a need for collaborative and integrative health promotion and injury prevention programs and interventions to help curb this menace. Moreover, students who are susceptible to unintended injuries such as older adolescents, victims of bullying, those who participate in physical education, those who often involve in fights, truants, and those who have psychological distress should be sensitized to take measures that will reduce their level of susceptibility. First aid treatment services should also be made available in schools to treat victims of unintended injuries.

Author Contributions: R.G.A. and A.-A.S. developed the study concept and performed the data analysis. R.G.A., A.-A.S., S.A.B., J.E.H.J., and B.O.A. drafted and revised the manuscript critically for its intellectual content. All authors have read and agreed to the published version of the manuscript.

Funding: This research received no external funding.

Institutional Review Board Statement: Not applicable.

Informed Consent Statement: Not applicable.

Data Availability Statement: The data for this study are available from WHO: https:/ /www.who. int/ncds/surveillance/gshs/ghanadataset/en/ (accessed on 1 February 2020).

Acknowledgments: We acknowledge the WHO for providing us with the data on which the findings of this study were based. The authors sincerely thank Bielefeld University, Germany for providing financial support through the Institutional Open Access Publication Fund for the article processing charge.

Conflicts of Interest: The authors declare no conflict of interest.

\section{References}

1. Han, L.; You, D.; Gao, X.; Duan, S.; Hu, G.; Wang, H.; Liu, S.; Zeng, F. Unintentional injuries and violence among adolescents aged 12-15 years in 68 low-income and middle-income countries: A secondary analysis of data from the global school-based student health survey. Lancet Child Adolesc. Health 2019, 3, 616-626. [CrossRef]

2. Muula, A.S.; Siziya, S.; Rudatsikira, E. Prevalence and socio-demographic correlates for serious injury among adolescents participating in the Djibouti 2007 Global School-based Health Survey. BMC Res. Notes 2011, 4, 372. [CrossRef]

3. World Health Organization. World Report on Child Injury Prevention; World Health Organization: Geneva, Switzerland, 2008.

4. Hay, S.I.; Abajobir, A.A.; Abate, K.H.; Abbafati, C.; Abbas, K.M.; Abd-Allah, F.; Abdulkader, R.S.; Abdulle, A.M.; Abebo, T.A.; Abera, S.F.; et al. GBD 2016 DALYs and HALE Collaborators. Global, regional, and national disability-adjusted life-years (DALYs) for 333 diseases and injuries and healthy life expectancy (HALE) for 195 countries and territories, 1990-2016: A systematic analysis for the Global Burden of Disease Study 2016. Lancet 2017, 390, 1260-1344.

5. Salam, R.A.; Arshad, A.; Das, J.K.; Khan, M.N.; Mahmood, W.; Freedman, S.B.; Bhutta, Z.A. Interventions to prevent unintentional injuries among adolescents: A systematic review and meta-analysis. J. Adolesc. Health 2016, 59, S76-S87. [CrossRef]

6. Kyu, H.H.; Pinho, C.; Wagner, J.A.; Brown, J.C.; Bertozzi-Villa, A.; Charlson, F.J.; Coffeng, L.E.; Dandona, L.; Erskine, H.E.; Ferrari, A.J.; et al. Global and national burden of diseases and injuries among children and adolescents between 1990 and 2013: Findings from the Global Burden of Disease 2013 Study. JAMA Pediatrics 2016, 170, 267-287. [PubMed]

7. WHO. Adolescents: Health Risks and Solutions. 2018. Available online: https://www.who.int/news-room/fact-sheets/detail/ adolescents-health-risks-and-solutions (accessed on 1 February 2020).

8. Al-Hajj, S.; Nehme, R.; Hatoum, F.; Zheng, A.; Pike, I. Child school injury in Lebanon: A study to assess injury incidence, severity and risk factors. PLoS ONE 2020, 15, e0233465. [CrossRef] [PubMed]

9. Kendrick, D.; Hayes, M.; Ward, H.; Mytton, J. Preventing unintentional injuries: What does NICE guidance mean for primary care? Br. J. Gen. Pract. 2012, 62, 62-63. [CrossRef] [PubMed]

10. Vecino-Ortiz, A.I.; Jafri, A.; Hyder, A.A. Effective interventions for unintentional injuries: A systematic review and mortality impact assessment among the poorest billion. Lancet Glob. Health 2018, 6, e523-e534. [CrossRef]

11. Beck, N.I.; Arif, I.; Paumier, M.F.; Jacobsen, K.H. Adolescent injuries in Argentina, Bolivia, Chile, and Uruguay: Results from the 2012-2013 Global School-based Student Health Survey (GSHS). Injury 2016, 47, 2642-2649. [CrossRef] [PubMed]

12. Peltzer, K.; Pengpid, S. Unintentional injury and social correlates among in-school adolescents in seven Caribbean countries. Mediterr. J. Soc. Sci. 2014, 5, 2321. [CrossRef]

13. Denny, V.C.; Cassese, J.S.; Jacobsen, K.H. Nonfatal injury incidence and risk factors among middle school students from four Polynesian countries: The Cook Islands, Niue, Samoa, and Tonga. Injury 2016, 47, 1135-1142. [CrossRef]

14. Peltzer, K. Injury and social determinants among in-school adolescents in six African countries. Inj. Prev. 2008, 14, 381-388. [CrossRef] [PubMed] 
15. Pengpid, S.; Peltzer, K. Unintentional injuries and socio-psychological correlates among school-going adolescents in Mozambique. Vulnerable Child. Youth Stud. 2020, 15, 32-39. [CrossRef]

16. Peltzer, K. Prevalence and social correlates of injury among in-school adolescents in Botswana. Afr. Saf. Promot. A J. Inj. Violence Prev. 2009, 7.

17. Wilson, M.L.; Kamala, B.A.; Dunlavy, A.C.; Kigwangalla, H.A. Demographic and contextual infl uences in injury risk among adolescents in a low-income country setting: Results from a school-based survey in Tanzania. Afr. Saf. Promot. A J. Inj. Violence Prev. 2012, 10, 41-50.

18. Hasim, M.H.; Fatimah, S.; Shahida, N.; Hatta, M.; Naim, M.; Hiong, T.G.; Rosnah, R. Socio-Demographic and Behavioral Factors for Serious Injury among Adolescents in Malaysia. Health 2015, 7, 1651. [CrossRef]

19. Jansen, L.; Bärnighausen, T.; Wilson, M.L. Injuries among adolescents in Greenland: Behavioural and socio-economic correlates among a nationally representative sample. PeerJ 2020, 8, e8605. [CrossRef]

20. Peltzer, K.; Pengpid, S. Unintentional injuries and psychosocial correlates among in-school adolescents in Malaysia. Int. J. Environ. Res. Public Health 2015, 12, 14936-14947. [CrossRef]

21. Peltzer, K.; Pengpid, S. Nonfatal injuries and psychosocial correlates among middle school students in Cambodia and Vietnam. Int. J. Environ. Res. Public Health 2017, 14, 280. [CrossRef]

22. Pengpid, S.; Peltzer, K. Unintentional injuries and socio-psychological correlates among school-going adolescents in four ASEAN countries. Int. J. Gen. Med. 2019, 12, 263. [CrossRef]

23. Peltzer, K.; Pengpid, S. Injury and social correlates among in-school adolescents in four Southeast Asian countries. Int. J. Environ. Res. Public Health 2012, 9, 2851-2862. [CrossRef] [PubMed]

24. Pengpid, S.; Peltzer, K. High prevalence of unintentional injuries and socio-psychological correlates among school-going adolescents in Timor-Leste. Int. J. Adolesc. Med. Health 2020, 1. ahead-of-print. [CrossRef]

25. Senterre, C.; Levêque, A.; Dramaix, M.; Piette, D. Prevalence, patterns and associated factors of injuries in school-aged Cameroonian children. Univers. J. Public Health 2014, 2, 97-109. [CrossRef]

26. Yu, J.O.; Kim, M.S. Factors associated with unintentional injuries to Korean adolescents at school: A multilevel study. J. Korean Acad. Community Health Nurs. 2016, 27, 337-345. [CrossRef]

27. Morna, M.T.; Appiah, A.B.; Akakpo, P.K.; Rahman, G.A.; Derkyi-Kwarteng, L.; Baidoo, R.; Berndtson, A. Epidemiology of childhood injury-related deaths: Review of mortality data at the Cape Coast Teaching Hospital. PAMJ One Health $2020,1$. [CrossRef]

28. Ohene, S.A.; Tettey, Y.; Kumoji, R. Injury-related mortality among adolescents: Findings from a teaching hospital's post mortem data. BMC Res. Notes 2010, 3, 124. [CrossRef]

29. Zagel, A.L.; Cutler, G.J.; Linabery, A.M.; Spaulding, A.B.; Kharbanda, A.B. Unintentional injuries in primary and secondary schools in the United States, 2001-2013. J. Sch. Health 2019, 89, 38-47. [CrossRef]

30. WHO. Global School-Based Student Health Survey (GSHS). 2014. Available online: https://www.who.int/ncds/surveillance/ gshs/en/ (accessed on 1 February 2020).

31. WHO. Global School-Based Student Health Survey (GSHS) Purpose and Methodology. 2014. Available online: https://www. who.int/ncds/surveillance/gshs/methodology/en/ (accessed on 1 January 2020).

32. Von Elm, E.; Altman, D.G.; Egger, M.; Pocock, S.J.; Gøtzsche, P.C.; Vandenbroucke, J.P. Strobe Initiative. The Strengthening the Reporting of Observational Studies in Epidemiology (STROBE) Statement: Guidelines for Reporting Observational Studies. Int. J. Surg. 2014, 12, 1495-1499. [CrossRef] [PubMed]

33. Wahdan, M.M.; Sayed, A.M.; Abd Elaziz, K.M.; El-Hoseiny, M.M.; Al-Gwaily, M.M. Prevalence of injuries among high school students in Eastern and Western parts of Cairo, Egypt. Injury 2016, 47, 2650-2654. [CrossRef]

34. Ruiz-Casares, M. Unintentional childhood injuries in sub-Saharan Africa: An overview of risk and protective factors. J. Health Care Poor Underserved 2009, 20, 51-67. [CrossRef] [PubMed]

35. Alonso-Fernández, N.; Jiménez-García, R.; Alonso-Fernández, L.; Hernández-Barrera, V.; Palacios-Ceña, D. Unintentional injuries and associated factors among children and adolescents. An analysis of the Spanish National Health Survey. Int. J. Public Health 2017, 62, 961-969. [CrossRef] [PubMed]

36. Cai, W.; Gao, Y.; Yang, W.; Cheng, F.; Tang, D.; Li, L. Physical activity-related injury and its associated factors among middle school students in southern China. Int. J. Environ. Res. Public Health 2018, 15, 1244. [CrossRef] [PubMed]

37. Albashtawy, M.; Al-Awamreh, K.; Gharaibeh, H.; Al-Kloub, M.; Batiha, A.M.; Alhalaiqa, F.; Hamadneh, S. Epidemiology of nonfatal injuries among schoolchildren. J. Sch. Nurs. 2016, 32, 329-336. [CrossRef]

38. Carmeli, E.; Azencot, S.; Wertheim, M.; Coleman, R. Sports injuries in students aged 12-18 during physical education classes in Israel. Biol. Sport 2003, 20, 271-280.

39. Pengpid, S.; Peltzer, K. Bullying victimization and externalizing and internalizing symptoms among in-school adolescents from five ASEAN countries. Child. Youth Serv. Rev. 2019, 106, 104473. [CrossRef]

40. Rudatsikira, E.; Mataya, R.H.; Siziya, S.; Muula, A.S. Association between bullying victimization and physical fighting among Filipino adolescents: Results from the Global School-Based Health Survey. Indian J. Pediatrics 2008, 75, 1243-1247. [CrossRef]

41. Peltzer, K.; Pengpid, S. Physical fighting and social correlates among in-school adolescents in the Caribbean. Mediterr. J. Soc. Sci. 2014, 5, 531. [CrossRef] 